\title{
VELÁZQUEZ EN EL PURGATORIO: LOS DÍAS Y LOS TRABAJOS DE UN CIENTÍFICO EN CALIFORNIA
}

\author{
POR
}

\author{
SALVADOR BERNABÉU ALBERT
}

Escuela de Estudios Hispano-Americanos (CSIC)

Siguiendo los proyectos del visitador malagueño José de Gálvez, el científico criollo Velázquez de León se ausentó de la Universidad de México y pasó dos años en la lejana península de California. El estudio de este episodio poco conocido de su vida nos revela la diversidad y complejidad de las relaciones sociales en uno de los lugares más remotos de la colonia. Velázquez fracasó en sus intentos por mejorar la minería local y en sus medidas como lugarteniente del visitador, pero escribió varias descripciones de gran interés y ayudó a medir el Paso de Venus desde su residencia de Santa Ana. Su afición a las cartas, a las fiestas y a las mujeres servirá para humanizar una figura demasiado encasillada en laboratorios, oratorios y respetables instituciones ilustradas.

Palabras clave: Minería, Reformismo Borbónico, José de Gálvez, Baja California, Velázquez de León.

\section{INTRODUCCIÓN ${ }^{1}$}

Las reformas carolinas en el Norte de México partieron de un ambicioso plan de modernización y racionalización de la política diseñada para el lejano Septentrión, con el que se quería fomentar la minería, la agricultura, el comercio, el poblamiento, la occidentalización de los pueblos indios y la instauración de la fiscalidad y la justicia real. Todo ello con el fin último de expandir la soberanía hispana hasta las últimas islas del frío (Alaska) y de diseñar una

1 Este trabajo se enmarca en el proyecto de investigación «Las fronteras y sus ciudades: herencias, experiencias y mestizajes en los márgenes del imperio hispánico (siglos XVI-XVIII» (HUM2007-64126) del Ministerio de Ciencia e Innovación. 
eficaz y férrea línea de presidios y misiones que frenaran los intentos de penetración extranjera en el corazón argentífero de México.

La aplicación de estas reformas fue posible gracias a un notable movimiento de personas que se expandieron por todos los puntos cardinales del Gran Norte. Entre 1764 y 1771, treinta y cinco batallones de soldados fueron enviados al continente americano, buena parte de ellos a la Nueva España, a los que habría que unir los numerosos grupos de misioneros y funcionarios que cumplieron las órdenes de sus superiores. Junto a ellos, mestizos, indios, negros, chinos - filipinos - , criollos y europeos de varias nacionalidades se unieron a la empresa de demarcar y poblar el Norte. Dentro de este heterogéneo grupo, destacaron por sus contribuciones al conocimiento de la geografía y la naturaleza norteñas los científicos: comunidad todavía poco definida y entre cuyos integrantes más destacados habría que contar —aparte de algunos misioneros- con marinos, ingenieros militares, naturalistas, astrónomos, cartógrafos, etcétera. La mayoría de ellos cultivaron varias especialidades a la vez y, salvo raras excepciones, su paso por el Septentrión fue temporal, reintegrándose a sus colegios, cuarteles y destacamentos de origen una vez terminados sus trabajos o comisiones en la frontera.

Junto a los peninsulares, los científicos criollos participaron de formar activa en el reconocimiento del virreinato, en ocasiones formando parte de expediciones lideradas por foráneos, pero otras veces tomando la iniciativa y encabezando interesantes viajes, en particular a los territorios fronterizos o interiores, muchos de ellos tan sólo parcialmente conocidos después de dos siglos y medio de colonización. Uno de ellos protagoniza este trabajo: Joaquín Velázquez de León, quien dejó su cátedra en la Universidad de México para acompañar al visitador José de Gálvez en su expedición al Noroeste, si bien sus pasos se detuvieron en la península de Baja California, en donde residió durante casi dos años y medio, realizando diversos trabajos científicos que le dieron fama tanto dentro como fuera de la Nueva España.

\section{VELÁZQUEZ DE LEÓN: UNA VIDA PARA LAS CIENCIAS Y LAS ARTES}

Velázquez de León pertenece al selecto grupo de criollos que lideraron la ciencia ilustrada en la Nueva España junto a José Antonio de Alzate, José Ignacio Bartolache y Antonio de León y Gama. Todos ellos van a compartir una gran dedicación, el carácter autodidacta y asistemático de sus trabajos, la curiosidad enciclopédica, la finura en las observaciones y el deseo de participar en la comunidad científica internacional. Este pequeño grupo de profesores y clérigos fundamentaba sus actividades en la utilidad social de la ciencia y sus valores, si bien sus biografías muestran las dificultades y los empeños por 
introducir la ciencia moderna en el virreinato. Los integrantes del grupo coincidieron también en el fervor por su patria: la que quisieron conocer (de ahí el empeño en dibujar buenos mapas), inventariar (para contrarrestar las acusaciones vertidas en Europa de ser una tierra menor) y optimizar (introduciendo las novedades e inventos más recientes).

Entre ellos, Velázquez de León ocupa un lugar destacado por las numerosas disciplinas científicas que abarcó, por la calidad de sus trabajos y por la dimensión social y política de muchas de sus iniciativas: era un hombre cercano a virreyes, visitadores, arzobispos y nobles. Velázquez tuvo un papel relevante en la política reformista, colaborando asiduamente con los principales grupos de poder y con los responsables de la administración virreinal. Esta dimensión, aunque se hace patente en varios momentos de su vida, no ha sido estudiada en profundidad. En este trabajo tampoco la abordaremos, dadas las características del monográfico en el que se integra, pero sí estudiaremos sus actuaciones políticas en el Septentrión Novohispano: concretamente su estancia en la península californiana.

Hasta ahora, los historiadores - encabezados por Roberto Moreno de los Arcos, el mejor especialista de nuestro científico - se habían centrado en tres aspectos: el análisis de las reformas propuestas para la minería californiana, las observaciones astronómicas realizadas con motivo del Paso de Venus y los comentarios sobre la naturaleza y las posibilidades de comercialización de algunos de sus productos. Estas temáticas estaban relacionadas con los contados documentos disponibles ${ }^{2}$. Afortunadamente, en estos últimos años, la documentación sobre Velázquez de León ha ido ampliándose gracias a la labor de las archiveras y archiveros de México y España, conociéndose más información sobre los años universitarios, la gran labor fundacional del Tribunal de Minería y nuevos datos sobre su estancia en la Baja California. En el Museo Naval de Madrid se guardan los cálculos e informes que Velázquez realizó durante la observación del Paso de Venus por el disco del Sol el 3 de junio de

2 En el libro más completo que se ha dedicado a Velázquez de León, Roberto Moreno señala: «De todos los escritos, memorias y cartas de nuestro autor sobre las Californias, sólo nos queda una carta de 12 y 13 de septiembre de 1768 en que describe el país y las actividades de Gálvez y suyas, y el extenso informe de 1771 al virrey en que, al mismo tiempo que hace un análisis de la explotación minera en la Nueva España, describe las mejoras de su invención que se aplicaron en las minas de Baja California». Moreno, 1977: 51-52. Las cartas fueron editadas por Ignacio del Río en Velázquez de León, 1975: 51. Existe una edición en inglés en Engstrand, 1976: 26-60. El original se custodia en la Colección de manuscritos Hernández y Dávalos, de la Latin American Manuscripts, University of Texas Library (Austin, Texas). En cuanto al informe minero de 1771, véase Bernabéu, XXXIX (Madrid, 1987): 103-122. El original se encuentra en la Biblioteca Nacional de México, manuscrito 58. 
1768. Y, además, hay un grupo de cartas de gran interés para estudiar la dimensión socio-política de la labor de nuestro científico, quien quedó al mando del distrito sur de la península como subdelegado de la visita de José de Gál$\mathrm{vez}^{3}$. En este periodo nos centraremos para analizar los trabajos en el desierto de una figura central de la Ilustración novohispana, ya que una mirada detenida - microhistórica - nos revelará nuevas facetas y aspectos del gran científico mexicano.

Joaquín Luciano Manuel Velázquez de León, hijo del alférez Francisco Antonio Cárdenas Velázquez de León y de Isabel Francisca de Ruinosera, nació en la hacienda minera de Santiago Acebedocla, cerca de Sultepec, el 21 de junio de 1732. Su padre trabajaba en la citada hacienda junto a su tío Fernando Miguel, pero, al morir su progenitor, el joven pasó a vivir bajo la tutela de su tío, el bachiller Carlos Celedonio Velázquez de León, hombre de gran cultura e influencia en la capital virreinal, pues era catedrático de filosofía y retórica, vicerrector del Colegio Seminario de México y cura del Sagrario Metropolitano. El joven Joaquín tuvo también un preceptor indígena llamado Manuel Asencio. Su educación reglamentada la inició como interno en el Colegio Tridentino, donde superó la carrera de leyes, pasando el 24 de marzo de 1754 al colegio de Santa María de Todos los Santos, donde se dedicó al estudio de las matemáticas en un seminario creado por él mismo en 1765. Con el tiempo, varios compañeros y aficionados se unieron al grupo; uno de ellos fue Antonio de León y Gama, quien lo sustituyó en la cátedra de Astrología de la Real y Pontificia Universidad - lograda por Velázquez el 13 de noviembre de 1765 - cuando aceptó el ofrecimiento del visitador general José de Gálvez de acompañarlo en su expedición al Noroeste del virreinato.

Velázquez de León era una persona brillante, activa, seductora, ambiciosa, inquieta, curiosa y de gran inteligencia, lo que explica la diversidad de empresas acometidas al mismo tiempo con excelentes resultados. El citado Antonio de León y Gama escribió que «a más del estudio de la Jurisprudencia, que era su principal profesión como Abogado de la Real Audiencia, se ocupaba, sin embarazarse, en los de la Química y Metalurgia, en el de Física experimental, Historia Natural y Ciencias Matemáticas; no olvidando las letras humanas, poesía y mitología.... $\rangle^{4}$. De todas estas facetas, la composición de poemas y leyendas mitológicas con las que se adornaban los arcos triunfales de santos, reyes y virreyes le dieron gran popularidad ${ }^{5}$. Pero la astronomía y la minería serían las disciplinas que más le apasionaban.

\footnotetext{
3 La correspondencia se encuentra en el Museo Naval, Madrid (MN), legajo 330.

4 Ramírez, 1888: 10.

5 Velázquez fue el autor del arco triunfal que el ayuntamiento capitalino dedicó a la entra-
} 
Desde 1755, Velázquez realizó diversas observaciones astronómicas buscando corregir las tablas y cartas geográficas. Le obsesionaba encontrar las verdaderas coordenadas de México, meta que sólo logró cuando, a la vuelta de California, contando con instrumentos de alta precisión — propiedad de la Real Academia de París - , realizó exactas mediciones. Pero sería la minería, arte al que estaban unidas varias generaciones de sus antepasados, la que acaparó su atención antes y después de su visita al Septentrión. Es bien conocida su asociación con el minero español Juan Lucas de Lassaga para analizar y buscar soluciones a los problemas que aquejaban a la minería novohispana. Ambos personajes trabajaron en la adaptación a las minas mexicanas de un horno de fundición inglés, cuya forma y características habían sido enviadas desde España. Velázquez y Lassaga construyeron uno para la capital y otro para Atotonilco el Chico.

Otra iniciativa de ambos personajes, junto al minero José de la Borda, fue una representación en la que solicitaban, con argumentos de peso, la rebaja del precio del azogue, al que culpaban de la decadencia de los reales mineros de la Nueva España ${ }^{6}$. La petición fue bien recibida por las autoridades, quienes la enviaron a la corte para su estudio. Paralelamente a este asunto, Velázquez y Lassaga presentaron al virrey Croix un nuevo método para el apartamento del oro y la plata, que fue ensayado con éxito a pesar de los primeros informes negativos ${ }^{7}$.

Esta frenética actividad de proyectos y ensayos protagonizados por Velázquez de León tuvo una consecuencia inesperada: el visitador José de Gálvez se fijó en él para que le acompañara en su viaje al prometedor Noroeste ${ }^{8}$. Velázquez era un candidato ideal, pues su saber enciclopédico no se quedaba sólo en el nivel especulativo y académico, sino que lo llevaba al terreno de la práctica, aptitud y disposición que, sin duda, tuvo que valorar mucho don José de Gálvez, quien estaba decidido a fomentar las minas del Noroeste como principal

da del virrey marqués de Cruillas en 1761 y de los realizados para conmemorar la coronación de Carlos III. Velázquez de León, 1978.

6 La representación es de 1766 o principios de 1767.

7 Testimonio de los autos hechos sobre el nuevo apartamento de oro y plata y proposición hecha por don Juan Lucas Lassaga, regidor de esta nobilísima ciudad, contador de menores y albaceazgos de ella, y el licenciado don Joaquín Velázquez de León, Archivo General de Indias, Sevilla (AGI), México, legajo 1267, ff. 13-23.

8 No sabemos con certeza cuándo se conocieron, pero por un escrito de Lassaga sabemos que Joaquín fue el autor de las Ordenanzas para la buena dirección de la fábrica y estanco de la pólvora y de los reglamentos para el beneficio de salitres y azufres, que, refrendados por el visitador, fueron editados por el virrey Croix el 20 de octubre de 1766. Probablemente, el encuentro de ambos personajes se produjo en el citado año. 
motor del crecimiento económico de esa zona. Nuestro abogado se encargaría concretamente de «la cultura de aquellas minas de una manera suficiente a instruir a los de allí, y que pudiese servir de modelo para las Provincias interiores, y tal vez en los nuevos descubrimientos $\rangle^{9}$. Es decir, Velázquez debería examinar las minas, mejorar los métodos empleados, capacitar a los trabajadores locales y contribuir al aumento de la extracción de plata y oro. No en vano, la expedición se dirigía a territorios considerados — por el vulgo y por muchos funcionarios y escritores - como grandes placas de oro y plata, a las que simplemente había que aplicar los esfuerzos y los métodos adecuados para que contribuyeran a llenar las exhaustas arcas reales.

\section{De MÉXICO A CALIFORNIA}

La comitiva del visitador José de Gálvez partió de la ciudad de México el 5 de abril de 1768 . Velázquez, que contaba con treinta y cinco años y fama de sabio, se unió a la comitiva llevando entre su abultado equipaje varios instrumentos astronómicos ${ }^{10}$. Durante la expedición, que atravesó varias ciudades novohispanas antes de alcanzar el Pacífico en el puerto de San Blas de Nayarit, realizó diversas mediciones, las que completó en el transcurso de la navegación a California. La travesía del golfo la realizó en el paquebote La Concepción, cuyo piloto, Jorge Estorace, le prestó sus instrumentos - más precisos- para que siguiera haciendo mediciones astronómicas. En su compañía viajaron los secretarios del visitador y parte de la comitiva, quienes alcanzaron la playa de Cerralvo, en el sureste de la península, el 14 de junio. Aunque llevaron en su conserva la balandra Sinaloa durante varias jornadas, en la que viajaba don José de Gálvez, la perdieron de vista la noche del 28 al 29 de mayo, por lo que arribaron a California sin el visitador general ${ }^{11}$. Este llegaría veinte días más tarde —el 5 de julio de 1768 —, permitiendo que Velázquez y los secretarios - siguiendo sus instrucciones - realizaran la descarga del paquebote y su envío de nuevo a San Blas, donde escaseaban los barcos y se multiplicaban las misiones navales.

Una vez realizado este importante encargo, los expedicionarios se dirigieron a la hacienda de Santa Ana, distante doce lenguas, que se convirtió en el

\footnotetext{
9 Ramírez, 1888: 12.

10 Por ejemplo, Velázquez condujo un barómetro con el que hizo mediciones en el Golfo de California, en Santa Ana y en el Mar del Sur.

11 Carta de Juan Manuel de Viniegra y Miguel José de Azanza al marqués de Croix, ensenada de Cerralbo, 19 de junio de 1768, Archivo General de la Nación, México (AGN), California, volumen 76 , ff. 84-86r.
} 
campamento de la visita y en el centro administrativo del Distrito Sur de la California $^{12}$. Previamente, los recién llegados habían adquirido los modestos edificios e instalaciones para laborar el mineral que tenía su dueño, Manuel de Ocio, quien en 1771 informó al gobernador Armona cómo se produjo la compra:

Velásquez vino a esta a decirme que el señor visitador le había enviado a que vendiera las casas en nombre de su majestad. A eso respondí que, en siendo para su majestad y gusto suyo, que fuera [en] hora buena. Después me citaron para que pusiera evaluadores de ellas, que evaluaran junto con los que pusieran de su partido. No hubo ninguno que lo quisiera hacer, porque estaban aspaventados en vista de los muchos que vinieron, y entre ellos estos señores dos abogados que eran los que hacían y deshacían. Así, no hubo nadie de mi parte que quisiera asistir a dicho avalúo, motivo porque los dichos las evaluaron en mil quinientos pesos y eso dieron por ellas, siendo así que ni la madera me pagaron ${ }^{13}$.

Ocio, antiguo soldado de los jesuitas, enriquecido gracias a un golpe de suerte - acumuló una gran cantidad de perlas en la playa de la misión de San Ignacio tras un huracán, invirtiendo las ganancias en expediciones perlíferas y empresas mineras - , había superado las trabas y obstáculos de los jesuitas, logrando explotar algunos yacimientos que serían el embrión del único enclave secular no controlado por la Compañía de Jesús en toda la península californiana. El minero, sorprendido por las exigencias de los expedicionarios, tuvo que vender a regañadientes la hacienda y las casas de Santa Ana que tanto trabajo le había costado levantar, además de varias minas.

Este paraje, único en toda la península, fue el elegido por Gálvez para residir y comenzar las reformas. Permaneció en el lugar unos seis meses y, tras su marcha a Sonora, se convirtió en el hogar de Velázquez de León, por lo que nos detendremos brevemente para describirlo. Santa Ana fue visitada y bautizada por el misionero jesuita Ignacio María Nápoli en 1721, quien edificó una capillita que pronto quedó abandonada. Sin embargo, el territorio fue recorrido frecuentemente por los soldados del presidio de Loreto. El capitán Esteban Rodríguez Lorenzo señaló en un informe de 1740 las excelencias del lugar, situado a seis leguas de la costa: "país muy ameno y abierto con admirables llanadas, lomerías y varios arroyos con agua que salen de una sierra que está enfrente, mirando al sur, y la que llaman de Santa Ana y los naturales le llaman

12 Gálvez dividió la California en dos departamentos, dirigidos por un gobernador que residiría en Loreto, capital del Departamento del Norte. El del Sur, con capital en el real de Santa Ana, estaba administrado por un teniente de gobernador.

13 Carta de Manuel de Ocio a Armona, La Fundición, 18 de junio de 1770, MN, legajo 330, f. 139r-v. Sobre este importante personaje, véase el artículo de Serrera, 5 (Cádiz, 1980): 113-128. 
Marinó. Hay en ellas muy admirables maderas de gueribos, robles, encinos y minerales de plata» ${ }^{14}$.

En 1748, el citado Manuel de Ocio inició la explotación minera, si bien para entonces los jesuitas habían fundado hasta cuatro misiones en sus proximidades: Nuestra Señora del Pilar de La Paz (1720-1749), Santiago de los Coras (1721), San José del Cabo Añuití (1730) y Todos Santos (1733). El singular enclave serrano en el territorio misional fue creciendo con los años gracias al descubrimiento de nuevas vetas y a la llegada de soldados jubilados, sus familiares, antiguos vaqueros, indios de la contracosta (principalmente yaquis y mayos) y algunos gambusinos aventureros ${ }^{15}$. Durante la estancia de Velázquez de León, la región minera se componía de varios núcleos habitados por entre cinco y veinte familias, la mayoría de escasos recursos, rodeados por pequeños y dispersos ranchos de ganado. Los más importantes de esos núcleos fueron El Triunfo (1751), San Antonio (1756), Las Gallinas, El Realito del Oro y, por supuesto, Santa Ana (1748) ${ }^{16}$.

El aumento de enclaves generó, entre otros problemas, el de los límites territoriales con las misiones ignacianas, que mantuvieron constantes conflictos con los mineros. Otro asunto de confrontación fue la negativa de los jesuitas a vender alimentos - principalmente granos, verduras y frutas frescas - a los reales, siempre con carencias a pesar del establecimiento de algunos ranchos ganaderos en las proximidades de ellos; causa también de nuevos conflictos por la costumbre de dejar libres las reses por los montes y lomeríos, confundiéndose las pertenecientes a los religiosos con las de los mineros ${ }^{17}$.

Los diversos testimonios contemporáneos coinciden en la modestia de la residencia de Gálvez y Velázquez de León. La mayoría de los pobladores vivían una existencia precaria, a excepción del citado Manuel de Ocio y de dos o tres mineros más. Según el padre Baegert:

Los que viven en estas minas, grandes y chicos, blancos y negros, todos juntos, suman a lo más unas 400 almas, y son, en parte, españoles nacidos en América, en

14 Descripción y toponimia, 1974: 12. El real de Santa Ana se encontraba en la sierra montañosa central de la región sudcaliforniana, que alcanza hasta 2000 metros de altitud y divide la parte sur de la península en dos: al oriente, las laderas alcanzan las costas del Pacífico mediante una serie de playas y acantilados con escasez de agua y poca ocupación humana; al occidente, el descenso es menos pronunciado, formando las laderas unos cañones profundos que desaguan en varias llanuras. Estas últimas conforman un amplio territorio que riegan varios arroyos procedentes de las serranías y algunos riachuelos en la estación de lluvias. Las planicies sudcalifornianas fueron el hábitat principal de los indios pericúes.

15 Baegert, 1942: 61-62.

16 Sobre el establecimiento y desarrollo de los reales mineros, véase Amao, 1997.

17 Clavijero, 1982: 216. 


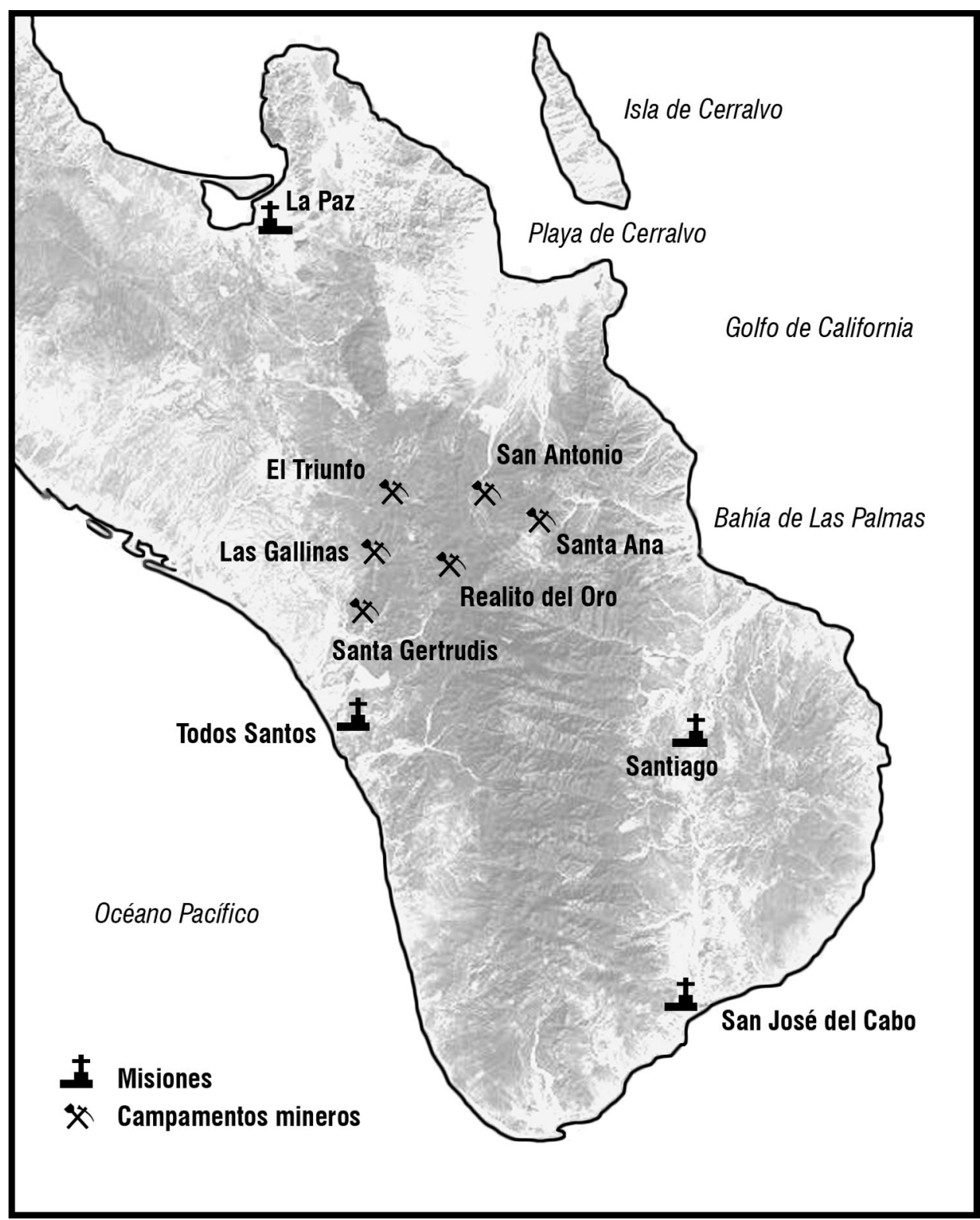

Mapa de la zona minera de Sudcalifornia. Circa, 1768.

parte indios del otro lado del Golfo, porque los indígenas californianos tienen tan pocas ganas de dejarse enterrar vivos por la plata, como ahogarse por las perlas. La pobreza y miseria son mucho más grandes que el número de estos mineros; la tierra 
sólo produce un pasto un poco más abundante que en otras partes, pero la poca plata no alcanza para traer el pan desde el otro lado del mar, de modo que la mayoría de estos mineros pueden hablar de buena suerte si consiguen comer, además de su carne, una tortilla algunas veces al año. Ha habido allí familias españolas que se vieron en la necesidad de buscar el sustento, vagando por los campos como los indios. Como es la alimentación, así es la ropa, y muchos de los niños ya crecidos de los españoles, andan en las minas como los californios, es decir, más que semidesnudos ${ }^{18}$.

Este territorio, poblado por una dispersa y mísera comunidad, fue elegido por Gálvez como lugar de residencia y laboratorio privilegiado de sus reformas. Además de las casas, Velázquez también se apropió de otros bienes de Ocio, como instrumentos (hachas, azadones y cargas de leña), un horno de carbón, varias camas, la sal que tenía guardada, etcétera. De nada le sirvió al viejo Ocio el proclamar ante los recién llegados sus numerosos trabajos para levantar el enclave minero en la exclusiva California Jesuita y los numerosos metales y perlas entregadas al monarca español como quinto real: «nunca me participaron nada de lo que se ejecutaba con mis bienes, siendo así que en aquel tiempo no había tal abasto ni poder mío mas que su mero gusto; en todo y por todo a mí, según lo hecho, me mirarían como cadáver de la otra vida o como reo de lesa majestad» ${ }^{19}$.

Las reclamaciones de Ocio fueron respondidas por Velázquez y Gálvez con graves acusaciones. Las cuatrocientas personas que vivían en el distrito minero soportaban una existencia infeliz y llena de miserias: "como unos cautivos en Argel». El minero, «que ha sido un cuervo que criaron los jesuitas», se había convertido en un déspota, acaparando las tierras y ganados que deseaba. $\mathrm{Su}$ avaricia no tenía límites, habiendo hecho estanco de todas las minas pretéritas, presentes y futuras, de manera que ninguno de los pobres mineros podía trabajar ninguna veta sin que Ocio «fuese a la mano». Y cuando las cosas iban bien, los mineros le entregaban todo el metal de fuego que saliese, «porque él solo tiene función, que se reduce a dos hornos de soplo de agua en que guisa sus metales conforme al método de Fray Junípero y está todavía metiendo en el horno los mismos fierros y escorias que metió ahora treinta años» ${ }^{20}$.

Las críticas se extienden también al sistema de trabajo, porque los operarios laboraban a ración y salario mensual: aquélla consistente en un pedazo de carne y, en ocasiones, un poco de maíz, mientras el salario se pagaba en efectos de escasa calidad que Ocio traía en sus barcos de la contracosta y cuyo va-

18 Baegert, 1942: 62.

19 Carta de Manuel de Ocio a Armona, La Fundición, 18 de junio de 1770, MN, legajo 330, f. $138 \mathrm{v}$.

20 Velázquez, 1975: 34. 
lor incrementaba en un doscientos o trescientos por cien. En definitiva, Velázquez compara a Manuel de Ocio con el personaje bíblico del Naval Carme$l o$, rico y avariento granjero, poseedor de grandes rebaños, que despreció al rey David.

Pero hay que recordar que la modesta hacienda de Santa Ana, con todas sus carencias, permitió que Gálvez y su séquito tuvieran las mínimas necesidades cubiertas y que las diversas construcciones que formaban el modesto complejo minero de Ocio se convirtieran en el espacio en donde Velázquez de León comenzase, sin dilación, las experiencias científicas.

\section{EL PARAÍSO (DESPUÉS PURGATORIO) CALIFORNIANO}

Velázquez de León, contagiado del entusiasmo del visitador general por las posibilidades de promoción del Noroeste de la Nueva España, desarrolló una actividad frenética durante los días previos a la llegada del malagueño, que resumió en una carta donde alaba las excelencias de la península de California. La actitud del científico influyó, a su vez, en el visitador, quien redactó largas y encomiables misivas al rey y al virrey que muchos, posteriormente, tacharon de utópicas y fantasiosas ${ }^{21}$.

Cuando José de Gálvez desembarcó en la península californiana, presa de un excesivo optimismo, creyó encontrar una tierra fértil — pues hacía poco que había llovido en abundancia-, colmada de productos para comerciar y con un clima sano para levantar poblaciones. Además estaba habitada por indios dóciles que, liberados del yugo jesuita, pronto se incorporarían a la sociedad occidental bajo la protección real. Los resultados posteriores mostraron las alucinaciones del malagueño, relatadas sin piedad por su secretario Manuel de Viniegra. Sin embargo, los investigadores no han tenido en cuenta que la actitud de Gálvez era frecuente en las primeras décadas de las reformas carolinas (1764-1787). Según el profesor Céspedes del Castillo:

Inicialmente convencidos, como típicos ilustrados, de que para cambiar una sociedad bastaba con cambiar sus leyes y legislar de manera clara, precisa y acorde

21 Del Río, 2007: 173-188. Las expectativas de Gálvez sobre el Noroeste eran anteriores, como he apuntado, pero las afirmaciones del científico lo ratificaron en sus sospechas y muchas de las ideas de Velázquez las encontramos recogidas en la correspondencia del visitador. Evidentemente, ni el visitador ni nuestro científico fueron los únicos en creer en la potencialidad de la California. Véase, por ejemplo, el Informe del estado de la minería en el Departamento del Sur de la California, Real de Santa Ana, 16 de noviembre de 1767, AGN, Californias, vol. 36, exp. 5. 
con la razón natural, se percibe en todos sus designios, preceptos y escritos en general un acusado triunfalismo. La explicable tendencia de los gobernantes a creerse su propia retórica y propaganda, tendencia que a veces les lleva a confundir sus intenciones con sus logros, determinaría que sus grandilocuentes rasgos de optimismo perdurasen en los documentos, aun después de que la experiencia les obligase a cambiar sus iniciales expectativas por un desánimo creciente ${ }^{22}$.

Esta tendencia general explica también el optimismo de Velázquez de León, quien bien pudo - en un viaje de ida y vuelta - contagiar a su protector de las maravillas de la California, pues, como confesó en carta a un amigo, mientras estuvo sin el visitador (del 14 de junio al 5 de julio), «me había instruido del estado y circunstancias de este país ${ }^{23}$, realizando varias excursiones por los alrededores de Santa Ana. Por lo que es posible que en su primer encuentro con José de Gálvez le enumerase y ratificase los prodigios de la península.

De sus observaciones dedujo que California — en realidad una pequeña parte del extremo meridional por él recorrida - era de una «fertilidad prodigiosa», capaz de abastecer de abundante grano al resto de la península. El sabio mexicano imputa la terrible miseria en la que vivían sus moradores sólo a la «falta de gobierno y cuidado», que, en primer lugar, achaca a los jesuitas ${ }^{24}$, en segundo lugar a los soldados que se habían encargado de las misiones por unos meses y, por último, al tirano de Manuel de Ocio. Para agrado del visitador y del virrey, señaló sin tapujos que los productos ya conocidos — plata, oro, perlas y sal—, como los recientemente descubiertos - grana, añil, palo brasil, palo Campeche, piedras de alumbre y una resina, que considera «el mejor incienso del mundo»-, serían suficientes para sostener económicamente la península, no necesitando en adelante los subsidios enviados anualmente desde México.

Poco antes de viajar a California, el intendente de la Casa de la Moneda de México, Pedro Núñez de Villavicencio, había escrito que Velázquez de León unía a su sabiduría en varios rubros su mucho juicio y moderación. Evidentemente, estas últimas cualidades las dejó en la capital novohispana, pues, en California, el científico criollo se sumergió en un optimismo desbordado al describir la fertilidad prodigiosa de los campos californianos, el extraordinario

22 Céspedes, 1999: 205.

23 Velázquez, 1975: 15.

24 En carta fechada el 12 de septiembre de 1768, Velázquez escribe: «Los regulares expulsos manejaron estas misiones con tan miserable abandono que al salir de ellas quedaron sin instrumentos para cultivar la tierra y tan escasas de indios las que podían producir granos, que en una, por ejemplo, de esta parte del sur, se perdieron casi todos los frutos este año y el pasado y entre ellos doscientas fanegas de arroz, por no haber más de quince naturales capaces de trabajar y que no pudieron levantar la cosecha, cuando en otras muchas de terreno estéril había numerosas rancherías vagantes en los montes y luchando con el hambre». Velázquez, 1975: 47. 
tamaño del ganado y la exquisitez de su carne, que «no tienen semejantes en Nueva España» ${ }^{25}$. No le irían a la zaga la fecundidad de los mares y la multitud de animales terrestres. En fin, un paraíso terrenal confirmado por lo sano del aire y por la ausencia de chinches, pulgas y piojos.

Para no dañar el idílico cuadro, Velázquez atenúa y suaviza los peligros y las incomodidades de la California, o simplemente las omite, como el excesivo calor, los destructores tornados, la falta de agua dulce o la escasez de alimentos. Si hace referencia a las numerosas e incómodas plantas espinosas, sólo es para confirmar que era tierra proporcionada para el plantío y cultivo de la grana. Y al hablar de los efectos negativos de la langosta en los cultivos, que tantos quebraderos de cabeza dieron a los jesuitas, Velázquez considera «que podrá extinguirse sin grave dificultad $\gg^{26}$. No hay límites para el entusiasmo. Como su protector malagueño, el científico criollo da por sabido y verdadero lo que sólo son noticias vagas o generales, como la abundancia de las perlas - que ya estaban extinguidas en muchos lugares por la sobreexplotación-o «los muchos minerales que encierra esta península», imaginados antes de su descubrimiento. $\mathrm{O}$ exagera la calidad de la grana, que no cederá — según su dictamen- a la más fina cochinilla mixteca.

Reinando temporalmente sobre este idílico paraje, Gálvez dio inicio a la tarea de reglamentar y de reformar la vida peninsular. Comenzó por pedir informes del terreno y sus habitantes a los misioneros franciscanos y a los antiguos capitanes, pero, antes de que todos ellos estuvieran en sus manos y los estudiase detenidamente, ya empezó a actuar. Su objetivo principal era que la California se sostuviera por sus medios y no costase nada a las cajas reales. Para ello elaboró docenas de instrucciones sobre cómo explotar y comercializar todos los productos posibles, por más modestos e insignificantes que fueran (las piedras de fusil) o de resultados inciertos (la cochinilla). Comentario aparte merece la minería, que analizaremos en el siguiente apartado.

Un segundo objetivo del visitador malagueño fue diseñar y potenciar el poblamiento del territorio, convencido de que la parte del sur de la península tenía una gran importancia estratégica para defender el Noroeste novohispano. En particular le interesa reforzar el extremo sur (Cabo San Lucas y la misión de San José), puesto que allí se detenía el galeón de Manila. En adelante, este cabo austral también serviría como punto de refugio y de control de los viajes marítimos españoles que se adentraran en el océano Pacífico. Gálvez elaboró instrucciones para crear un poblado cerca del Cabo San Lucas, repobló las misiones sureñas,

25 Velázquez, 1975: 17.

26 Velázquez, 1975: 16-17. 
diezmadas a causa de las epidemias, y creó varias milicias provinciales, poniendo a la cabeza de las mismas a los principales mineros de la zona.

Una tercera tarea de Gálvez en el austro peninsular fue el arreglo de los barcos y la redacción de las instrucciones para las expediciones marítimas que se dirigían a ocupar los puertos de San Diego y Monterrey, ya reconocidos por los marinos antiguos, pero que ahora adquieren actualidad por los rumores de la proximidad de los rusos. Tras el arreglo de los barcos, Gálvez visitó la misión principal - Loreto - y abandonó la península rumbo a Sonora, donde le esperaban nuevos trabajos y proyectos.

Con la salida del visitador, el Departamento del Sur quedó bajo el mando del científico mexicano. Junto a él, José de Gálvez había nombrado, a propuesta de Velázquez, a Manuel de Espinoza como comisario y teniente de gobernador del departamento, responsable, en consecuencia, tanto de la justicia como de la hacienda real, incluido un almacén instalado en Santa Ana ${ }^{27}$. Y para la gestión del ramo de minas se eligió a Bernardo Moreno y Casto y a Manuel García Morales, como primer y segundo administrador. Estos últimos personajes acumulaban otros cargos, pues además de ser capitanes de caballería de las milicias provinciales, Manuel García Morales era juez administrador de los ramos de salinas y perlas, y comisario de las nuevas poblaciones, tierras y aguajes. Sin embargo, los dos funcionarios estaban sujetos a los dictámenes de Velázquez de León, acumulando el científico mucho, por no decir todo, el poder, y no sólo en el ámbito minero, pues como subdelegado de la visita tenía la responsabilidad de impulsar las reformas diseñadas por el visitador malagueño ${ }^{28}$. Sin embargo, la realidad pronto se impuso, llenando de desazón a nuestro científico: el paraíso se convirtió en un purgatorio del que intentó escapar en varias ocasiones.

\section{LA MINERÍA EVANESCENTE}

Las expectativas que tanto Gálvez como Velázquez de León tenían de la minería peninsular eran desmedidas. Como ya señalé, el visitador confiaba en

27 Espinosa empezó a trabajar en su cargo el 13 de julio de 1768 con un sueldo anual de 1200 pesos.

28 Así queda demostrado en los dos últimos nombramientos: a Bernardo Moreno le ordena Gálvez, «que se arreglará a las instrucciones y órdenes que le diere dicho don Joaquín Velásquez, como su subdelegado inmediato y único, autor de tan importantes asuntos». Y en el correspondiente a Morales, se indica que «observará las órdenes de instrucciones que en punto de minería le diere mi inmediato subdelegado don Joaquín Velásquez de León». Informe de Bernardo Moreno y Castro y Manuel García Morales a Armona, MN, legajo 330, doc. 51, ff. $161 \mathrm{v}-162$ r. 
que el oro y la plata de California pronto sustituyeran el situado anual, pero, además, que el millón y medio de pesos que se esperaba obtener de sus minas pudiesen financiar las costosas reformas que necesitaban Sonora, Sinaloa y la Nueva Vizcaya. La presencia de Velázquez en la expedición responde justamente a la idea de impulsar el rápido establecimiento de una moderna minería (en métodos y máquinas). Para apoyar el proyecto, Gálvez no escatima esfuerzos ni gastos, contratando a un grupo de barreteros encabezados por José País, «el mejor minero de inteligencia de las minas de Guanajuato y otras partes». El minero se trasladó a California con un sueldo de treinta pesos semanales «para que dirija las obras y desagües y enseñe por onde deben trabajar para encontrar el metal» ${ }^{29}$. Además de esta ayuda humana, Gálvez consiguió del virrey Croix el envío de doscientos quintales de azogue, procedentes del almacén de Guadalajara, para fomentar la producción minera, que se vendían en Santa Ana a cien pesos el quintal.

Sin duda, Gálvez puso sus esperanzas en el aumento del rendimiento de las minas, gracias a las nuevas reformas e inventos que esperaba que Velázquez de León pusiera en marcha en colaboración con los expertos mineros guanajuatenses. Sin embargo, pronto aparecieron las dificultades. Durante los tres primeros meses, Velázquez tan sólo descubrió una gran veta cerca de la playa de Cerralbo, poniendo en ella toda su esperanza, pues las ya explotadas por Ocio, Pisón y otros mineros locales le parecieron que no pasaban «de una cosa muy regular», añadiendo «que debía exigirse más de unos países tan distantes y famosos, y muchos más de los informes que en México se nos habían hecho». Es decir, que los rumores que circulaban en la capital no se correspondían con la realidad encontrada ${ }^{30}$. También fue de la misma opinión José País, quien «desia que no servían solo por las tentaduras que hasia el Señor Velásquez, y algún metal que bido aquí dixo que todo eso era como la peor brosa de Guanajuato y esto no se escondía para decirlo» ${ }^{31}$.

Para remediar la ausencia de buenas vetas, Velázquez propuso un premio para el que descubriese nuevas minas, pero los resultados fueron poco halagüeños. Además, la organización de las expediciones terrestres y marítimas destinadas a ocupar el puerto de Monterrey y la necesidad de contar en la costa con hombres y herramientas para reparar los dos barcos de la jornada, que llegaron en pésimas condiciones, mermaron la capacidad de trabajo en las minas,

29 Carta de Ocio a Matías de Armona, La Fundición, 18 de junio de 1770, MN, legajo 330, f. 141r.

30 Velázquez, 1975: 15.

31 Carta de Ocio a Matías de Armona, La Fundición, 18 de junio de 1770, MN, legajo 330 , f. 141r. 
pues muchos hombres se dedicaron a calafatear y reparar los citados navíos. E, incluso, en ocasiones, los mineros fueron enviados a la Alta California - a veces como castigo a sus faltas - u obligados a sembrar y recoger los frutos de las misiones ante la carencia de indios sanos.

Por tanto, la realidad de las minas californianas no se pudo ocultar por mucho tiempo. Conocemos por cartas de Ocio que los barreteros llegados desde Guanajuato estuvieron haciendo una noria, y en cuanto a José País, permaneció desde junio a diciembre en Santa Ana sin acercarse a las minas. Poco después, unos y otros fueron enviados de vuelta al Bajío debido a la pobreza de las vetas peninsulares ${ }^{32}$.

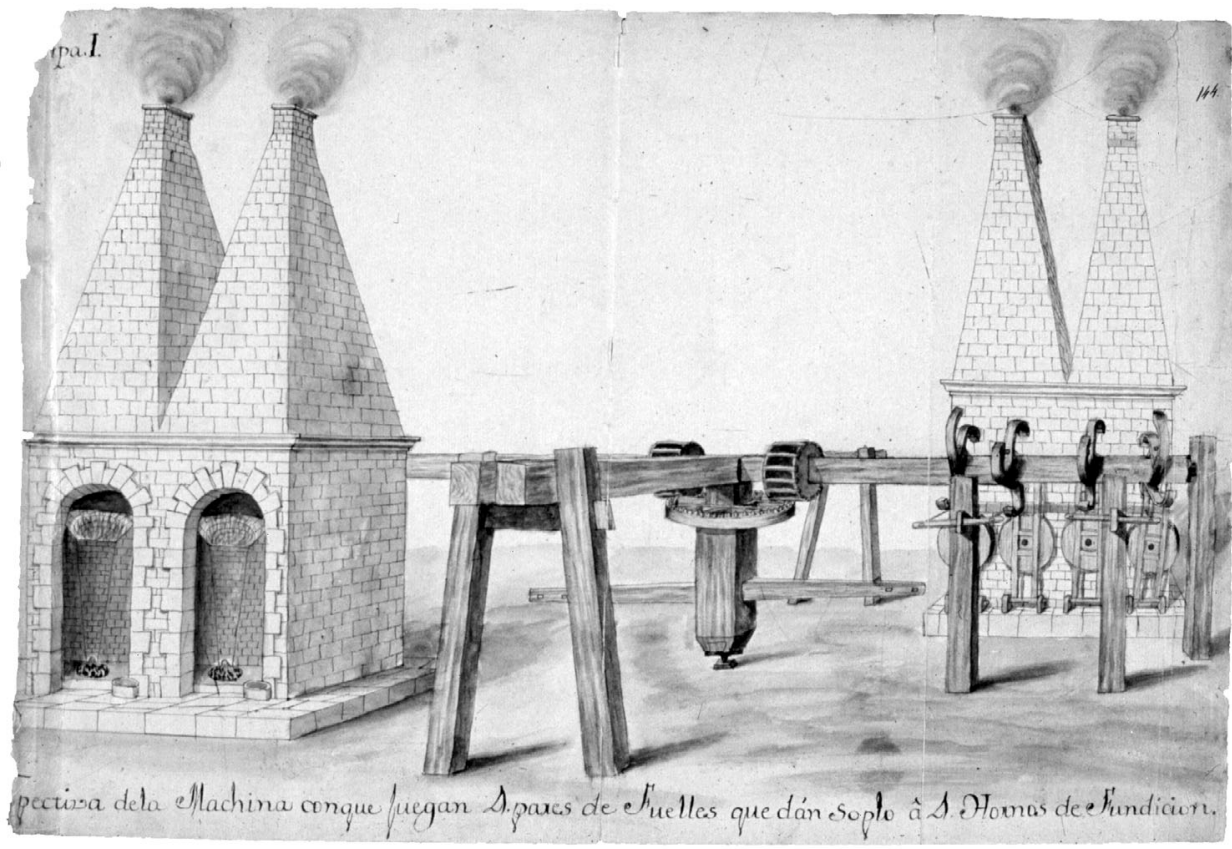

Perspectiva de la máquina. Informe de Velázquez de León, 1771. Archivo General de la Nación, México.

32 El obispo de Guadalajara comunicó al virrey, en carta fechada el 15 de febrero de 1769 , que habían regresado los mineros José Páez y Francisco Casas y los azogueros José Caracena y Vicente Busto, quienes le manifestaron el infeliz estado en que quedaba Gálvez. Serrera, 1980: 127. 
Sin paliativos, la reforma de la minería californiana fue un fracaso. Velázquez destruyó más que levantó y los nuevos inventos y modificaciones que introdujo - los cuales describió minuciosamente en su informe al virrey de 1771 - no sirvieron para potenciar la minería local, aunque sí se aprovecharon para otras explotaciones novohispanas, de mejores vetas y leyes. Sin embargo, los numerosos caudales empleados hasta entonces llevaron a Velázquez a encubrir la realidad al virrey Croix y a describir, en varias cartas y un informe, las numerosas labores realizadas, el éxito de las mismas y la esperanza de que pronto se lograría extraer gran cantidad de plata en el estéril desierto. El 28 de julio de 1769, un año después de su llegada, el científico criollo escribió al gobernante que: «Las principales minas de estos lugares de ruinosas, aterradas y extraviadas que estaban antes; se hallan hoy limpias, fortificadas y restituidas sus labores a la dirección de sus vetas $[\ldots]\rangle^{33}$. A pesar de estas labores de limpieza y consolidación, la mala calidad del mineral impidió que los trabajos velazqueños tuvieran éxito.

Velázquez optó, entonces, por atacar a los mineros locales, acusándolos de extraer mal los minerales, de no dejar pilares para su seguridad en los túneles abiertos y de abandonar las vetas a la menor borrasca: «En este estado se hallan casi todas, de suerte que para examinar los metales de estas vetas las he hecho picar en otras partes, sacando sólo de las minas viejas menos peligrosas y que para explorar sus planes no se ha necesitado aventurar dinero en faenas y limpias». Y todo para llegar a la misma conclusión: «en ellas he encontrado algunas borrascas y pocas labores con bastante metal a la verdad bien malicioso ${ }^{34}$. Es decir, que las vetas californianas eran pobres.

Ocio, Pisón y otros mineros no se quedaron callados. Manuel de Ocio, por ejemplo, criticó los desastres y despilfarros cometidos por Velázquez y sus compañeros, así como la ausencia de plata para enviar a la Caja de Guadalaja$\mathrm{ra}^{35}$. En sus palabras había mucho rencor, y no era para menos. En unos cuan-

33 Carta de Velázquez de León al virrey Croix, Real de Santa Ana, 28 de julio de 1769, MN, ms. 330, f. 129r.

34 Velázquez, 1975: 25-26.

35 Manuel de Ocio señaló que «Yo todos los años he enviado mis remesas y actual, cuando dichos señores vinieron, tenía como tengo cuarenta arrobas de plata que remitir a mi abiador». Frente a los nuevos métodos y supuestos arreglos de la minería local del científico, el viejo Ocio señaló que antes sacaban bastante plata, mientras «oy día no ay donde poderla sacar, solo en los terrenos pepenando podrán hayar algo». Carta de Manuel de Ocio a Armona, La Fundición, 18 de junio de 1770, MN, legajo 330, f. 140v. Por su parte, Gaspar Pisón acusó a Velázquez y a Espinosa de que no se le daban los bienes que necesitaba del almacén y de haberle quitado hombres y herramientas de sus explotaciones. Carta de Gaspar Pisón y Guzmán a Armona, puerto de la Valandra, 30 de agosto de 1770, MN, legajo 330, ff. 146r-147r. 


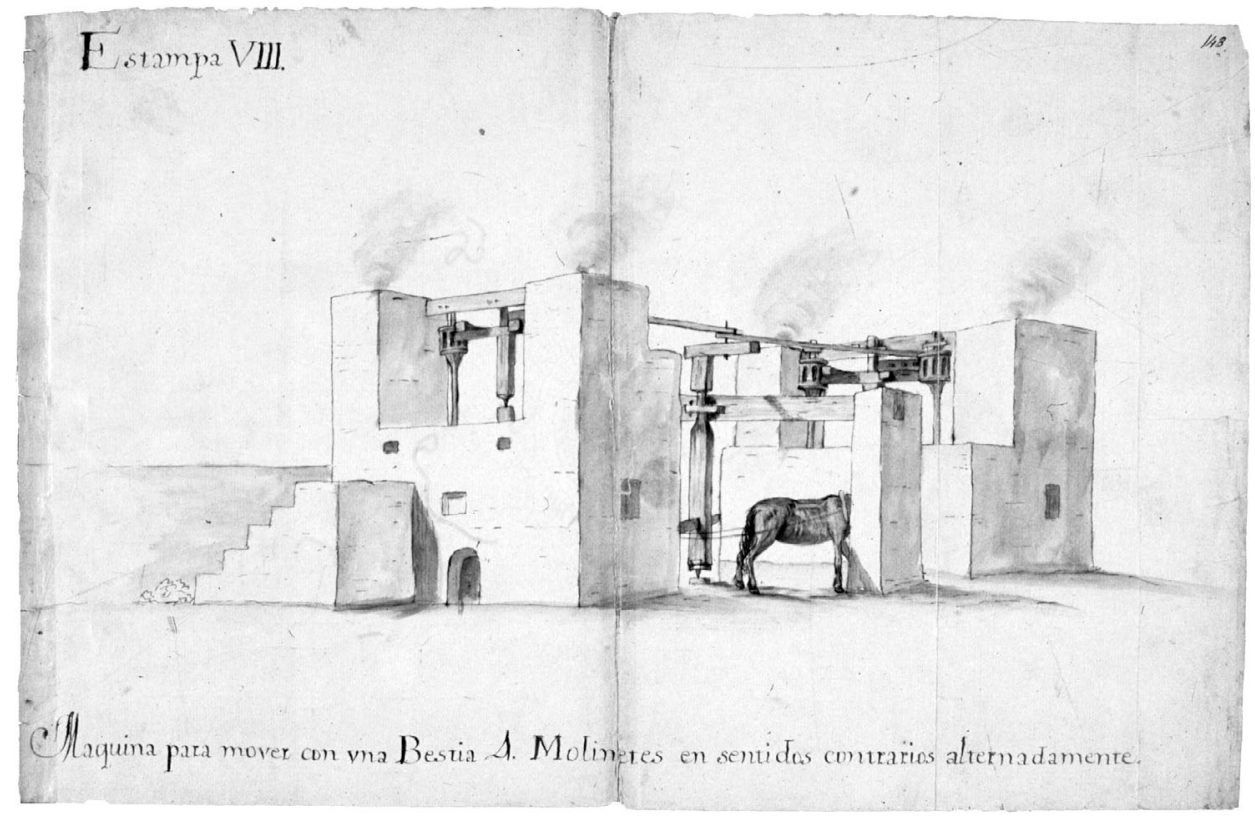

Máquina para mover con una bestia. Informe de Velázquez de León, 1771. Archivo General de la Nación, México.

tos días de junio de 1768 , los mineros locales habían sido despojados de sus casas y haciendas, y poco a poco los llegados se apoderaron de sus mejores hombres, herramientas, bestias, etcétera, además de ver mermados los ganados que vivían salvajes en los montes y que constituían la base de la alimentación de los mineros y sus familias. Pero las críticas en contra de Velázquez también partieron de otros residentes en el Distrito Sur, algunos de ellos funcionarios reales, ampliando las acusaciones más allá de los temas estrictamente mineros. Manuel García Morales escribió que «en todos asuntos se reconoce el ningún aumento y la total ruina de ellos como V.S. (aún sin mayor cuidado) irá mirando y justificando por ser todo patente y estar saltando a los ojos de la razón» ${ }^{36}$. Y Bernardo Moreno no le fue a la zaga, señalando, para descargo de su conciencia, «que la minería y la tierra la tiene perdida enteramente el señor don Juaquín velásquez como V.S. se puede informar de todos» ${ }^{37}$.

36 Carta de Manuel García Morales a Armona, Santa Ana, 17 de junio de 1770, MN, legajo 330 , f. 154 r.

37 Carta de Bernardo Moreno y Castro a Armona, Santa Ana, 18 de junio de 1770, MN, legajo 330, f. 155r. 
Comprobada la mala calidad de los minerales y las dificultades de sobrevivir en el antiguo paraíso, reconvertido en purgatorio tras la salida de Gálvez - ya que nuestro científico no tenía el poder de aquél para traer alimentos, mover personas y liderar las reformas-, el único deseo de Velázquez era regresar a la capital mexicana, por lo que instó al virrey a que le diera licencia. Su posición era incómoda, pues como subdelegado del visitador no sólo era el responsable de las minas, sino que también debía de contribuir al cumplimiento de las numerosas órdenes e instrucciones dejadas por José de Gálvez antes de partir hacia la contracosta ${ }^{38}$. La salida era, por tanto, la solución más fácil, si bien se fue complicando debido a la locura transitoria del malagueño en Sonora y a las dificultades que tuvo el virrey marqués de Croix para encontrar personas adecuadas que gobernaran la península.

\section{LOS PROBLEMAS DE SU ESTANCIA FORZOSA}

Durante los primeros meses de su estadía sin Gálvez en California, Velázquez vivió uno de los episodios más interesantes de su vida científica. En la lejana península coincidió con una expedición hispano-francesa, encabezada por el astrónomo galo Chappe d'Auteroche, con la misión de medir el Paso de Venus por el disco del Sol el 3 de junio de 1769. La trascendencia de esta medición - calcular la distancia de la tierra al astro rey- suponía el descubrimiento de la paralaje solar y, con ello, la medida del universo, por lo que es entendible la movilización de varios grupos de sabios internacionales, que se coordinaron para obtener el mayor número posible de mediciones ${ }^{39}$. Velázquez se ofreció a observar el raro fenómeno con los marinos españoles y los científicos galos en San José del Cabo, pero Chappe d'Auteroche lo convenció para que realizase sus mediciones en el real de Santa Ana. Así lo hizo, encontrándose sus resultados entre los mejores del planeta a pesar de no contar con el instrumental más moderno y adecuado.

Si embargo, Velázquez no pudo gozar de la conversación con el astrónomo real, pues murió poco después de la observación víctima de una epidemia que diezmó a varios miembros de la expedición y a cientos de indios del distrito sur. Velázquez recibió a los sobrevivientes en el real de Santa Ana, comprándole al albacea de Chappe d'Auteroche los libros y los instrumentos científi-

38 En carta de Velázquez al marqués de Croix, Real de Santa Ana, 28 de julio de 1769 (MN, legajo 330, ff. 129r-130v), le informa «haberme dejado aquí [Gálvez] con el uso de sus facultades a fin de promover los nuevos establecimientos, principalmente la reforma de la minería así en lo económico como en lo legal y político».

39 Bernabéu, 1998: 9-55. 
cos que había traído de Francia, con los que pudo hacer nuevas observaciones astronómicas en la península de California ${ }^{40}$.

Trascurrida esta visita, de nuevo California volvió a su cotidianidad y Velázquez escribió al virrey Croix el 22 de agosto de 1770 que dejaría la península en el primer barco que pudiera para explicarle sus trabajos ${ }^{41}$. La contestación fue que permaneciese hasta la llegada del nuevo gobernador, Matías de Armona. Así lo hizo, quedando Velázquez como máxima autoridad del Departamento del Sur. La hora de la salida de nuevo parecía acercarse cuando Armona llegó a Santa Ana el 13 de junio de 1770, pero el reciente gobernador encontró una carta del virrey en la que lo autorizaba a restituirse a su regimiento. La orden virreinal señalaba concretamente que, si Armona encontrase a su llegada a Velázquez de León, lo dejaría con el cargo de gobernador y podría regresar a México. Sin embargo, las graves acusaciones contra Velázquez vertidas por diversos habitantes y autoridades de la zona y la paralización de las reformas obligaron a Matías de Armona a quedarse e iniciar una pesquisa ${ }^{42}$.

Mientras trataba de paliar algunos de los problemas que aquejaban a la península desde la partida de José de Gálvez, como la falta de alimentos ${ }^{43}$, el gobernador pidió informes primero a Manuel García Morales y a Manuel Espinosa de los Monteros ${ }^{44}$, y el 26 de junio de 1770 a Joaquín Velázquez, deman-

40 Carta de Velázquez al marqués de Croix, Real de Santa Ana, 28 de septiembre de 1769, MN, legajo 330, f. 127r-v. Sobre los instrumentos, véase Moreno, 1974: 309-324. El virrey le comunicó que, por orden de la corte, debía devolver los libros e instrumentos, pues eran propiedad de la Real Academia de París.

41 El 22 de agosto de 1770, Velázquez escribió al virrey: «Como espero salga de aquí en el primer barco que llegue y tener la deseada satisfacción de besar a vuesa excelencia la mano e informarle de los asuntos que me tocan, no debo por ahora molestar más la superior atención de vuesa excelencia, ocupada en otros más graves». Carta de Velázquez a Croix, Real de Santa Ana, 22 de agosto de 1770, MN, legajo 330, ff. 133r-v: 122v.

42 Sobre estos trabajos, Rodríguez-Sala, 2003: 79-109. Los principales problemas que sufrían la península y los nuevos establecimientos de la Alta California eran la falta de abastecimiento, control y paga de soldados y marineros, la carencia de naves, la búsqueda de fuentes de riquezas para potenciar los nuevos establecimientos y la agilización de la administración en todos sus ramos y aspectos.

${ }^{43}$ La situación vivida en el primer semestre de 1770 fue muy difícil, pues, a la falta de víveres, se unió la epidemia que acabó con numerosas personas y los huracanes. Y en cuanto a los trabajos de las minas, se encontraban paralizados desde noviembre por falta de sal. Por ello, cuando en el mes de marzo llegó una pequeña lancha que traía dicho producto desde la isla del Carmen, el gobernador Armona la mandó a Sinaloa por maíz, si bien no encontró ninguna fanega por la hambruna que se vivía en la región. Sirvan estos datos para dar idea de la gravedad de la situación en la península californiana.

44 García Morales era «Juez administrador del Real Ramo y Quinto de Perlas, el de la sal y Comisario General de las nuevas Poblaciones en el Departamento del Sur de la California», 
dándole noticias sobre «lo que se ha sacado y ganado en ellas [las minas] desde que se empezaron a trabajar de cuenta de la expedición» ${ }^{45}$. Sin embargo, Velázquez no respondió, haciéndolo en su nombre el capitán de milicias Bernardo Moreno. Su informe fue demoledor, pues señaló que, desde que se habían empezado a trabajar las vetas californianas, las arcas reales estaban perdiendo dinero. Lo extraído oscilaba entre 215 y 218 marcos de plata de fuego, añadiendo: "Que hay como 18.000 quintales de metal para sacar la plata, los cuales podrán producir treinta y seis mil onzas a dos pesos cada quintal, de lo que deberá rebajarse el costo de su beneficio, que importarán como siete mil pesos (si se hiciere como yo deseo ejecutarlo) $\gg^{46}$. Agregando, además, que se les debía a los operarios de cinco a seis mil pesos.

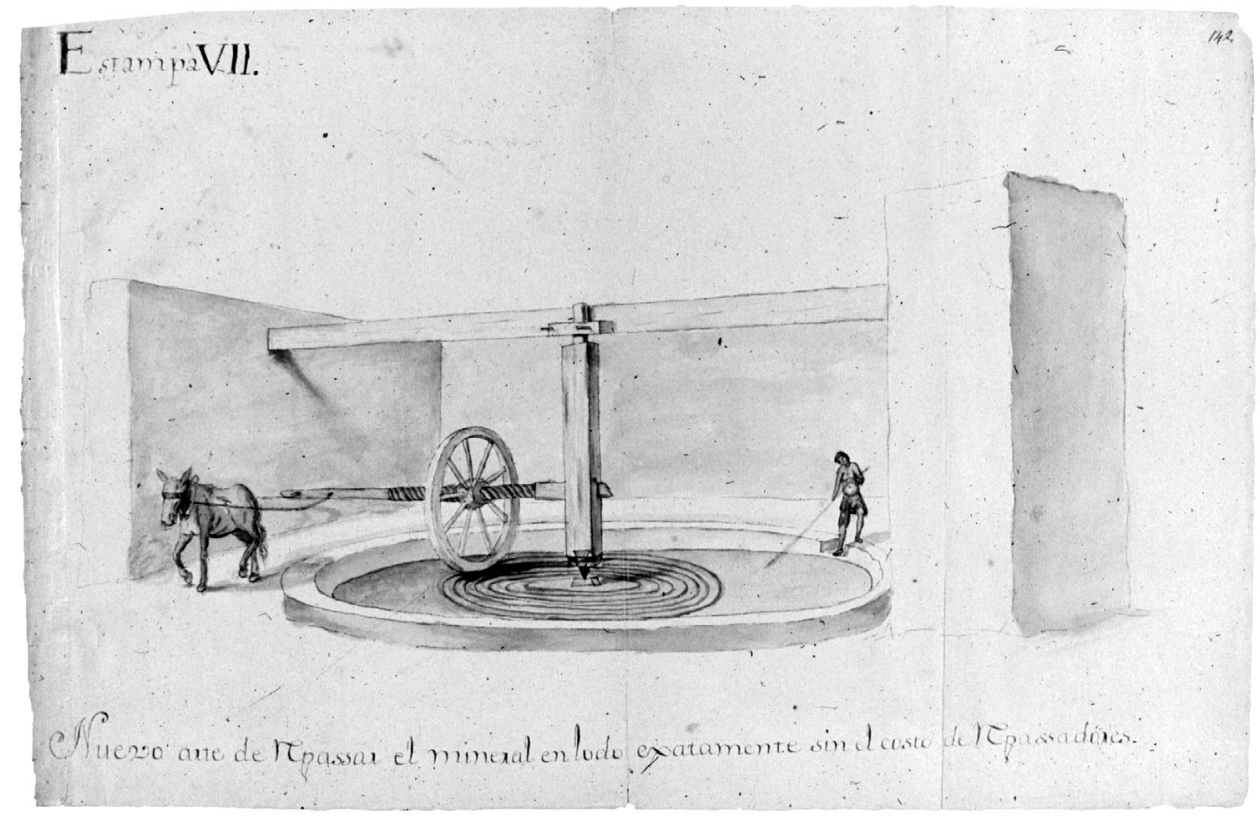

Nuevo arte de repasar el mineral. Informe de Velázquez de León, 1771. Archivo General de la Nación, México.

mientras Espinosa de los Monteros era comisario real de Santa Ana. Entre sus cometidos estaba el cuidado de los ramos de la Real Hacienda.

45 Carta de Armona a Velásquez, Real de Santa Ana, 26 de junio de 1770, AGN, California, legajo 76, f. 185 r.

46 Carta de Bernardo Moreno a Armona, Real de Santa Ana, 27 de junio de 1770, MN, legajo 330 , f. $185 \mathrm{r}-185 \mathrm{v}$. 
Velázquez de León se negó a comentar la escasa producción de metales, aunque este grave hecho no parece que afectara la relación con el gobernador. La razón quizás se encuentre en la naturaleza de la misión de nuestro científico, en el apoyo que le dispensaba Gálvez y en la solidaridad de dos funcionarios de mediano rango en la lejana frontera, además de que Armona no había recibido ninguna orden del virrey para inspeccionar sus trabajos. Así, el 29 de junio (tres días después de la petición de información de Armona) ${ }^{47}$, solicitó al virrey Croix que le autorizase a viajar a México para explicarle en persona los trabajos realizados en la lejana península. Esta maniobra, sin embargo, no le libró de la lluvia de acusaciones que recibió por parte de misioneros, curas, funcionarios y soldados. Los cargos y quejas que se vertieron sobre el sabio mexicano nos ofrecen una imagen muy diferente de la que teníamos hasta ahora del científico criollo.

\section{CON VeLÁZqueZ LLEGó EL ESCÁNDALO}

Como señalé anteriormente, la llegada de Matías de Armona al real de Santa Ana propició la denuncia de varios personajes notables del departamento sureño, quienes coincidieron en sus censuras al científico. El misionero de Todos Santos, fray Marcos de Lora, escribió al nuevo gobernador que las buenas costumbres habían desaparecido en el distrito por haber recaído su gobierno en don Joaquín Velázquez de León, quien vivía en un continuo escándalo. La desarreglada vida del científico criollo tuvo su origen en la amistad con dos trabajadores: Marcos Gragiola y José Manuel Eras y con sus respectivas mujeres, quienes, tras algunos días de fiestas y banquetes, pasaron a hospedarse en las casas reales. Aunque las fuentes no lo indican expresamente, se da a entender que ambas quedaron embarazadas del científico y que dieron a luz en las citadas casas reales. Los maridos consintieron estas relaciones ilícitas a cambio de dinero, favores y diversos bienes del almacén real. El misionero franciscano comunicó a Armona que «ya nadie dudaba de lo ilícito de aquellas amistades», pues regalaba y vestía a sus invitadas con ricas ropas que no se correspondían con su estatus. Además, Velázquez había manifestado su deseo de llevarse consigo a los dos matrimonios a México, lo que llenó de preocupación al turbado y diligente franciscano ${ }^{48}$.

47 Carta de Velázquez a Croix, Real de Santa Ana, 29 de junio de 1770, AGN, California, legajo 76, exp. 74, ff. 309r-310v.

48 Carta de Fray Ramos de Lora a Armona, misión de Todos Santos, 22 de junio de 1770, $\mathrm{MN}$, legajo 330, ff. $170 \mathrm{r}-171 \mathrm{v}$. 
Por otra parte, el párroco de Santa Ana, Isidro de Ybarzábal, además de los bailes, diversiones, fandangos y amancebamientos, denunció que Velázquez no cumplió el precepto pascual durante los años que residió en Santa Ana, al igual que dos de sus sirvientes ${ }^{49}$. Amonestado, el científico le respondió que ni él ni sus criados eran sus feligreses.

Pero desde el punto de vista político y de gobierno, más censurables fueron las constantes sesiones de juego y los excesos de alcohol que se celebraron de forma regular en las casas reales. El minero Pisón narró el sistema empleado: primero invitaban a comer a la víctima, luego le ofrecían bebidas en abundancia, tras lo cual, comenzaba el juego de albures, en el que participaban las dos concubinas. Todo ello en las casas reales, con acompañamiento de música y bailes a pesar de la prohibición expresa de Gálvez de que no se tolerasen los juegos de albures en la California.

Incumpliendo el bando, Velázquez fue invitando poco a poco a las personas acaudaladas del territorio, que perdían sistemáticamente sus ahorros, por lo que podemos afirmar que nuestro sabio era un excelente jugador (o sus competidores muy malos). Aunque los afectados fueron remisos en declarar las pérdidas, conocemos algunas cifras. Antonio Ocio, hijo del fundador de Santa Ana, malgastó entre doce y quince mil pesos, y Gabriel Pisón, más de cinco mil. Los dos quedaron arruinados ${ }^{50}$. Eugenio Olaechea, que tenía una fortuna estimada en miles de pesos de plata, también perdió su fortuna, al igual que José Manuel Estrada, que desperdició los pocos bienes que tenía, quedando imposibilitado para trabajar. Antonio Ocio, seguramente el que más dinero perdió en albures, señaló que, desde que llegó Velázquez y sus hombres, la tierra se convirtió en «amparo de pícaros y destrucción de hombres de bien $\rangle^{51}$. Reunida la información por Armona, escribió al virrey Croix que estos comportamientos fueron los que tuvo presente «para no encargarle el gobierno al tal subdelegado [Velázquez]» y en demorar su salida de la península ${ }^{52}$.

En defensa de Velázquez podemos argumentar que todos los que jugaron lo hicieron de forma voluntaria, si bien su comportamiento no fue el adecuado y,

49 Carta de Isidro de Ibarzábal a Armona, Santa Ana, 6 de julio de 1770, MN, legajo 330, ff. $148 \mathrm{r}-152 \mathrm{v}$.

50 Carta de Gaspar de Pisón y Guzmán a Armona, puerto de la Valandra, 30 de agosto de 1770, MN, legajo 330, ff. 146r-147v.

51 Carta de Antonio de Ocio a Armona, San Antonio, 16 de julio de 1770, MN, legajo 330, f. $145 \mathrm{v}$.

52 Carta de Armona a Croix, México, 24 de diciembre de 1770, en MN, legajo 330, ff. $156 \mathrm{r}-157 \mathrm{r}$. 
lo peor de todo, su enriquecimiento a costa de los principales mineros del sur empobreció aún más al departamento.

\section{PARA CONCLUIR}

Velázquez de León dejó California en el paquebote San Carlos a principios de noviembre de 1770, llegando a la ciudad de México el 11 de diciembre siguiente. Con él salieron también el gobernador Armona, el comisario Manuel de Espinosa y Manuel García Morales. Sólo quedó Bernardo Moreno y Castro como comisario y teniente de gobernador hasta nueva orden, aunque igualmente había solicitado su retiro al virrey ${ }^{53}$. Croix ordenó al científico que hiciese embarcar con él «la plata en pasta que haya perteneciente a la expedición en la comisaría del sur de esa Península ${ }^{54}$, pero sin censurarle su comportamiento ni la falta de resultados prácticos en la minería peninsular.

Tras su llegada a México, Velázquez prosiguió con éxito su carrera científica. El 11 de diciembre de 1770 prolongó la licencia de su cátedra universitaria durante varios meses, en los que redactó un informe sobre sus trabajos en California, que terminó el 9 de febrero de 1771. También realizó varias observaciones astronómicas con los instrumentos de última generación que consiguió en la península por la muerte de su propietario, el francés Chappe d'Auteroche, y confeccionó una carta geográfica del Noroeste del virreinato (Nueva Galicia, Sonora, Sinaloa, California y Nueva Vizcaya) en la que corregía los errores de latitud y longitud, hoy desaparecida. Por último, diseñó el arco triunfal que dio la bienvenida al nuevo virrey Antonio María de Bucareli y prosiguió con sus propuestas de mejorar la minería novohispana. Estos encargos, muchos de ellos oficiales, le obligaron a presentar su renuncia a la cátedra universitaria el 3 de febrero de 1773.

Frente a estos trabajos y laureles, no conozco ningún reproche oficial sobre sus actividades en la frontera. Pero en la lejana California, las minas quedaron abandonadas, la falta de gentes y dinero impidieron una rápida recuperación y las reformas de Gálvez quedaron, de momento, en el cajón. Velázquez presentó al virrey en el papel (el informe ya citado) un buen ramillete de innovaciones, pero que no potenciaron - sino todo lo contrario - la minería local. Su paso por Santa Ana fue negativo para la región, aunque las observaciones as-

53 Moreno a Armona, s. l., s. f., AGN, California, legajo 76, exp. 65, f. 262r-v. Antonio López de Toledo fue nombrado teniente de gobernador del Departamento del Norte.

54 Carta de Croix a Velázquez, México, 12 de noviembre de 1770, MN, legajo 330, f. $134 \mathrm{r}-\mathrm{v}$. 
tronómicas le dieron fama en las cortes ilustradas y los ensayos en el real de Santa Ana se aplicaron con éxito en otras minas novohispanas. El propio científico confesó a sus subordinados, cuando le recomendaban emplear otros métodos, que «es preciso hacerlo así porque importa poco el gastar mucho en experiencias de los que aquí no sirva para lograrlo con infinitas ventajas en otras partes ${ }^{55}$. En definitiva, Velázquez, que imaginó a California como un cielo, la perjudicó de tres maneras: al no responsabilizarse de los cometidos reformistas que le encomendó Gálvez, al destruir la minería local en su provecho (o en nombre del progreso de la minería) y en descapitalizar la región con las ganancias sacadas a los principales mineros gracias a los prohibidos juegos de albures.

\section{BIBLIOGRAFÍA}

Amao Manríquez, Jorge Luis, Mineros, misioneros y rancheros de la Antigua California, México, Plaza y Valdés-Instituto Nacional de Antropología e Historia, 1997.

Baegert, Juan Jacobo, Noticias de la península americana de California, México, Antigua Librería de Robledo, 1942.

Bernabéu Albert, Salvador, «Ciencia y Minería en Baja California: el informe de Joaquín Velázquez de León (1771)», Asclepio, XXXIX (Madrid, 1987): 103-122.

Bernabéu Albert, Salvador, Las huellas de Venus. El viaje del astrónomo Chappe d'Auteroche a Nueva España (1768-1769), México, Breve Fondo Editorial, 1998.

Céspedes del Castillo, Guillermo, Ensayos sobre los reinos castellanos en Indias, Madrid, Real Academia de la Historia, 1999.

Clavijero, Francisco Xavier, Historia de la Antigua o Baja California, estudio preliminar de Miguel León-Portilla, México DF, Porrúa, 1982.

Del Río, Ignacio, «Los sueños californianos de José de Gálvez», Ignacio del Río (comp.), El Noroeste del México Colonial. Estudios históricos sobre Sonora, Sinaloa y Baja California, México D.F., Universidad Nacional Autónoma de México, 2007: 173-188.

Descripción y toponimia indígena de California, 1740. Informe atribuido a Esteban Rodríguez Lorenzo, introducción y notas de Miguel León-Portilla, La Paz, Gobierno del Territorio de Baja California, 1974.

Engstrand, Iris Wilson, Royal Officer in Baja California, 1768-1770. Joaquin Velazquez de Leon, Los Angeles, Dawson's Book Shop, 1976.

55 Escrito de Bernardo Moreno y Castro y Manuel García Morales a Armona, Real de Santa Ana, 24 de octubre de 1770, MN, legajo 330, f. 167v. 
Moreno de los Arcos, Roberto, «Los instrumentos científicos del abate Chappe d'Auteroche», Anales de la Sociedad Mexicana de Historia de la Ciencia y la Tecnología, 4 (México DF, 1974): 309-324.

Moreno de los Arcos, Roberto, Joaquín Velázquez de León y sus trabajos científicos sobre el valle de México, 1773-1775, México DF, Universidad Nacional Autónoma de México, 1977.

Ramírez, Santiago, Estudio biográfico del señor don Joaquín Velázquez Cárdenas y León, primer Director General de Minería, México, Imprenta del Gobierno, 1888.

Rodríguez-Sala, María Luisa, Los gobernadores de las Californias, 1767-1804. Contribuciones a la expansión territorial y del conocimiento, México, Instituto de Investigaciones Sociales, UNAM-El Colegio de Jalisco-Gobierno del Estado de Baja California-Instituto de Cultura de Baja California-Universidad Autónoma de Baja California, 2003.

Serrera Contreras, Ramón, «Un andaluz, pionero en la explotación argentífera en la Baja California (1753-1783)», Gades, 5 (Cádiz, 1980): 113-128.

Velázquez de León, Joaquín, Descripción de la Antigua California: 1768, trascripción, presentación y notas de Ignacio del Río, La Paz, Ayuntamiento de La Paz, 1975.

Velázquez de León, Joaquín, Arcos de Triunfo, introducción de Roberto Moreno, México DF, Universidad Nacional Autónoma de México, 1978.

Recibido el 29 de septiembre de 2009

Aprobado el 19 de noviembre de 2009

\section{VELÁZQUEZ IN PURGATORY: THE WORKS AND DAYS OF A SCIENTIST IN CALIFORNIA}

While the Creole scientist, Velázquez de León, was pursuing the projects of a visitor from Malaga, José de Gálvez, he absented himself from the University of Mexico and spent two years in the distant peninsula of California. The study of this little-known episode in his life shows us the diversity and complexity of social relations in one of the most remote places in the colony. Velázquez failed in his attempts to improve local mining and in his efforts as right-hand man to the visitor, but he wrote several very interesting descriptions and helped to measure the Transit of Venus from his residence in Santa Ana. His fondness for cards, parties and women will help to show the human side of a figure who is too often typecast in laboratories, chapels and respectable learned institutions.

Key words: Mining, Bourbon Reformism, José de Gálvez, Lower California, Velázquez de León. 